\title{
Desafios para o Corredor Bioceânico e suas potencialidades turísticas: a questão da livre circulação de pessoas
}

\author{
Challenges for the Biocean Corridor and its tourist potentials: the question of \\ free movement of people
}

\section{Desafíos para el Corredor Bioceánico y sus potencialidades turísticas: la cuestión de la libre circulación de personas}

\author{
José Roberto da Silva Lunas ${ }^{1}$ \\ Aline Santos Melo ${ }^{1}$ \\ Maria Cristiane Fernandes da Silva Lunas ${ }^{1}$
}

DOI: http://dx.doi.org/10.20435/inter.v20iespecial.2328

\begin{abstract}
Resumo: A pesquisa explora os desafios da livre circulação de pessoas para fins turísticos com a implantação do Corredor Bioceânico que ligará Chile, Argentina, Paraguai e Brasil. A pesquisa realizou-se por meio de levantamento bibliográfico e documental, e entrevista a operadores de turismo e viajantes. Os resultados revelam entraves existentes para a circulação de pessoas nesses países, que poderão se reproduzir no trecho previsto para o corredor, e apontam a necessidade de se estabelecer novos acordos que aumentem o conforto e a segurança dos turistas no corredor.
\end{abstract}

Palavras-chave: América do Sul; rota de integração; Mercosul; fronteiras; turismo.

Abstract: The research explores the challenges of the free circulation of people for tourism purposes with the implementation of the Corredor Bioceânico that will link Chile, Argentina, Paraguay and Brazil. The research was done through a bibliographical and documentary survey, and interview to tour operators and travelers. The results reveal existing obstacles to the movement of people in these countries, which may be reproduced in the section expected for the corridor, and point out the need to establish new agreements to increase the comfort and safety of tourists in the corridor.

Keywords: South America; integration route; Mercosur; borders; tourism.

Resumen: La investigación explora los desafíos de la libre circulación de personas con fines turísticos con la implantación del Corredor Bioceânico que unirá Chile, Argentina, Paraguay y Brasil. La investigación se realizó por medio de levantamiento bibliográfico y documental, y entrevista a los operadores turísticos y viajeros. Los resultados revelan barreras existentes para la circulación de personas en esos países, que podrán reproducirse en el tramo previsto para el corredor, y apuntan la necesidad de establecer nuevos acuerdos que aumenten el confort y la seguridad de los turistas en el corredor.

Palabras clave: América del Sur; ruta de integración; Mercosur; fronteras; turismo.

\section{INTRODUÇÃO}

A ligação entre o Oceano Atlântico e o Pacífico faz parte do ideário de movimentos de integração dos povos sul-americanos há muito tempo. Este movimento, contudo, sempre foi impulsionado pelo sistema econômico. Embora esta ligação efetivamente já exista na parte sul da América do Sul com o movimento de cargas e de pessoas desde a região de Valparaíso no Chile até a região de Paranaguá no Paraná, sempre existiu o sonho de uma ligação das Regiões Norte e Centro-Oeste do Brasil com portos mais ao norte do Chile (BANCO NACIONAL DE DESENVOLVIMENTO ECONÔMICO E SOCIAL [BNDES], 2010). Tal ligação permitirá uma redução de custos de transporte para o sistema econômico com o incremento do movimento de cargas nos dois sentidos desde os portos de Antofagasta, Mejillones e Iquique, no Chile.

\footnotetext{
${ }^{1}$ Universidade Estadual de Mato Grosso do Sul (UEMS), Campo Grande, Mato Grosso do Sul, Brasil.
} 
Frequentemente os processos de implantação desses corredores têm negligenciado a discussão sobre a livre circulação de pessoas, que inclui trabalhadores e turistas, perpetuando elementos burocráticos e barreiras de integração. Embora nos estudos logísticos as referências ao turismo sejam recorrentes, a questão é apenas tangenciada sem um aprofundamento prático das suas implicações.

O interesse do presente trabalho é explorar a questão da livre circulação de pessoas sob o ponto de vista do setor da hospitalidade e do turismo, no novo Corredor Rodoviário Bioceânico, que está em planejamento, de modo a demonstrar aos atores econômicos a importância de um planejamento prévio que leve em consideração a redução do desconforto dos viajantes.

A grande questão que se procura responder é a de que talvez seja possível reduzir tal desconforto em que pese a necessidade de manutenção de barreiras que possam prover segurança, além das sanitárias e do equilíbrio dos diferentes segmentos financeiros envolvidos nas relações transfronteiriças.

A questão da circulação de trabalhadores, apesar de importante, não é foco do presente trabalho e é citada esporadicamente por suas ligações com a questão da livre circulação de pessoas. A abordagem do ponto de vista do turismo é necessária uma vez que este mantém hábitos distintos de pessoas que viajam para realizar atividades remuneradas ou não, como aponta Urry (1996). Trabalhadores, representantes comerciais, pesquisadores e caminhoneiros, ao transitarem regularmente nesses locais, mantêm conhecimentos e práticas que os permitem superar as dificuldades eventualmente impostas nas fronteiras. O turista, que viaja esporadicamente, não possui esse conhecimento e se irrita com as dificuldades encontradas, prejudicando, assim, a sua experiência de viagem.

Neste contexto, o objetivo geral do presente trabalho é analisar os elementos de restrição ou excesso de burocracia para a livre circulação de turistas com foco nas questões de segurança, dos meios de pagamento e da saúde.

Como se trata de um Corredor que ainda não existe de fato, já que parte da infraestrutura está em construção, este estudo é prospectivo. Em razão disso este trabalho foi elaborado por meio do método comparativo, com a utilização de revisão bibliográfica que procurou demonstrar os fenômenos ligados aos entraves para os turistas em outras situações de circulação entre fronteiras.

A abordagem metodológica é exploratória e descritiva dos fatores que podem influenciar no desenvolvimento de um futuro sistema turístico que se aproveite da intensificação do movimento do Corredor Bioceânico e estabeleça rotas e roteiros turísticos aproveitando as potencialidades turísticas nas regiões-alvo. Para tanto, foi aplicado um questionário com questões abertas enviadas por mensagens eletrônicas para operadores e agências que atuam nos quatro países envolvidos na implantação do Corredor Bioceânico, bem como para turistas que circularam recentemente por esses países por via terrestre. As questões versavam sobre os itens de segurança, meios de pagamento e saúde, que os turistas têm que enfrentar.

Este texto foi organizado em três partes principais, isto é, breve revisão teórica, apresentação dos trechos as serem atingidos pelo Corredor e os obstáculos e dificuldades que serão enfrentadas pelos turistas e, por fim, uma discussão sobre como esses elementos afetam o turismo e como o desconforto pode ser diminuído. 


\section{TURISMO, FRONTEIRAS E LIVRE CIRCULAÇÃO DE PESSOAS}

A questão da livre circulação de pessoas é um dos fatores mais críticos para um sistema turístico. A sua discussão envolve, principalmente, questões como a de segurança, de meios de pagamento e de saúde, além dos entraves burocráticos. O processo de globalização tem promovido o aumento da riqueza e mais empregos no mundo. Os blocos econômicos têm boa parte do mérito por promover esse crescimento. Isso, contudo, não significa necessariamente aumento da renda das pessoas.

A quantidade de empregos aumenta na indústria e nos serviços, especialmente no setor de hospitalidade e de turismo que, segundo a World Travel \& Tourism Council (WTTC, 2018), é responsável por um em cada 10 de empregos gerados no mundo. No mesmo estudo, esta entidade aponta para o desafio de diminuir os entraves para a circulação de pessoas e indica a evolução de equipamentos como o passaporte eletrônico e o reconhecimento facial e sistemas de biometria, que podem agilizar o trânsito de pessoas nas fronteiras.

Existem críticas acerca das estatísticas do WTTC, devido à inclusão de atividades indiretas e por considerar como turistas pessoas que não viajam com tal finalidade (HINTZE; ALMEIDA, 2014). Contudo, do ponto de vista da oferta, não há por que excluir a ampla gama de atividades que compõem a cadeia do turismo. Para Morrinson (2012), não há uma definição universalmente aceita para classificar as atividades incluídas, e o termo setor de hospitalidade e turismo é uma utilização livre. Para o fim a que se destina o presente artigo, este será o termo utilizado para abordar a análise das atividades implicadas. Especial atenção é dedicada às entidades que compõem a organização do setor de hospitalidade e turismo, assim entendidos os fornecedores, os transportadores, o comércio de viagens e a organização de marketing de destino (MORRINSON, 2012).

A discussão acerca da circulação de pessoas não é muito explorada pelos investigadores do setor de hospitalidade e turismo. Entretanto é de suma importância para este. Embora estejam diretamente ligados às questões de relações internacionais e diplomacia, os desafios que cercam segurança e o meios de pagamento acessíveis para o viajante atingem diretamente o setor.

No Brasil e no mundo se observa uma intensificação do número viagens internacionais, o que aumenta a importância do envolvimento acadêmico que ajude a desvendar os desafios que cercam este elemento fundamental para o turismo.

Há que se cuidar das expectativas da demanda, pois o turista é mais exigente que um viajante comum e seu olhar é mais crítico em relação às dificuldades que encontra em um sistema turístico que visita. Petrocchi (2001) aborda essa questão quando trata da gestão de polos turísticos, indicando caminhos para a organização das instituições de modo a diminuir problemas para os visitantes relacionados com as questões burocráticas.

Goeldner, Ritchie e McIntosh (2002) ressaltam a atenção inadequada que os sistemas turísticos recebem do ponto de vista jurídico, político e fiscal, que impactam em suas capacidades de competir pela preferência do turista. Os autores apontam para os exemplos das desregulamentações do Acordo de Livre Comércio Norte Americano (NAFTA) e a União Europeia (UE), que facilitam os sistemas de pagamento, trânsito e informações para os visitantes.

Na projeção da Organização Mundial de Turismo (WTO, 2018) o número de desembarques deverá continuar crescendo entre 3,5\% e 4,5\% nas Américas e, embora este crescimento seja menor que o da Ásia e da África, já representa um número muito expressivo, pois aumentou de 
15,3 milhões de desembarques no ano 2000, para 36,2 milhões em 2017, o que comprova o aumento da mobilidade no continente americano.

A questão dos entraves burocráticos que podem provocar impactos negativos na demanda turística é explorada por Bradbury (2012), ao demonstrar que os sistemas de segurança e controle de fronteira invariavelmente são fontes de incômodo para os turistas em todos os sistemas turísticos.

A fase inicial do ciclo de vida dos sistemas turísticos, conforme Butler (1980), caracteriza-se por um baixo número de turistas e é um momento em que existem estruturas mais precárias. Nessa fase um sistema turístico atrai apenas os chamados turistas alocêntricos, que são os que se sujeitam e até apreciam as estruturas precárias, em busca de opções mais aventureiras. Este é um dos perfis dos turistas estudados por Plog (2001). Pode-se especular que as primeiras experiências da criação de uma nova rota turística integrando Brasil, Paraguai, Argentina e Chile manterá as características acima e que os gestores e as organizações responsáveis pelos diversos segmentos que apoiam o sistema podem contribuir para aumentar ou para reduzir as dificuldades dos viajantes.

As dificuldades estão normalmente associadas aos controles de fronteiras e de conforto para os turistas em suas viagens internacionais. O rol principal de dificuldades está relacionado às questões sanitárias, de segurança e de meios de pagamento.

As questões sanitárias, de segurança e de acessibilidade e as consequentes barreiras impostas pelos servidores públicos são o alvo do estudo de Richter e Richter (1999). Eles escrevem sobre os desafios éticos ligados ao aumento das viagens internacionais. Dentre as principais causas para o aumento do rigor nas fronteiras estão o medo do terrorismo e a possibilidade de epidemias. A questão do terrorismo é explorada também por Richter e Waugh (1986), em que demonstram os impactos do terrorismo sobre o turismo.

Kwanisai et al. (2014) estudaram os efeitos do fluxo turístico nas fronteiras entre o Zimbabwe e a África do Sul e apresentaram os problemas enfrentados pelos turistas na fronteira e que causam as maiores reclamações, isto é, mau atendimento, infraestrutura deficiente, serviços de informações sobre procedimentos de fronteira incompletos ou inexistentes, excesso de procedimentos e, por último, a presença de agenciadores clandestinos ou fictícios de serviços, despachos aduaneiros e imigração, entre outros.

Mesmo os países que restringem, por questões políticas, o contato dos turistas com a população local, procuram diminuir as barreiras para a circulação de turistas na fronteira. Tais países veem o turismo como alternativa para o desenvolvimento econômico e buscam incrementar o fluxo turístico nas rotas disponíveis em um movimento de cooperação regional, como acontece nas fronteiras entre a China, o Laos e a Tailândia (XU; BAO; ZHOU, 2006). Estes autores apontam para os efeitos do rápido desenvolvimento turístico que, além de trazer benefícios do ponto de vista de emprego e do mercado para os produtos locais, também afetam negativamente do ponto de vista social, com o aumento do tráfico de drogas e da prostituição.

A questão dos meios de pagamento depende cada vez mais dos sistemas de Information Communications Technologies (ICT), que, além de prover informações mais detalhadas dos sistemas turísticos, podem facilitar sistemas de informações e trocas (MIDDLETON, 2002). A abordagem da evolução dos meios de pagamento por meio de ICTs e sua segurança é explorada por outros pesquisadores como Buhalis e Law (2008), além de Migiro e Ocholla (2005), que estudaram os efeitos do e-commerce para o turismo em média e pequena escala. $\mathrm{O}$ avanço dos 
cartões da presença de meios eletrônicos de pagamento deve facilitar as viagens de turismo em todo o mundo, mas, em sistemas que estão ainda na fase inicial de seu ciclo de vida, esses mecanismos são raros e podem demorar para serem implantados.

Do ponto de vista regional, a questão da integração do Mercosul e da livre circulação de pessoas é tema de um estudo em que Fernandes (2012) discute as dificuldades de integração por meio do Corredor Rodoviário Bioceânico e as ocorrências de problemas nas questões de saúde, de segurança e de sistemas de transporte. O tema da livre circulação de pessoas no Mercosul é estudado por Jaeger (1999) do ponto de vista da diplomacia e dos entraves à livre circulação de trabalhadores e que permite avaliar as deficiências das políticas relacionadas com a questão.

\section{RESULTADOS E DISCUSSÕES}

Projeta-se um Corredor Rodoviário Bioceânico que poderá integrar os sistemas turísticos de Brasil, Paraguai, Argentina e Chile. A percurso planejado deverá utilizar infraestrutura já construída em sua maior parte, com boas autoestradas no Chile e na Argentina, estradas mais improvisadas no Brasil e uma estrada em construção na região do Chaco, no norte do Paraguai. A proposta do percurso pode ser observada por meio do mapa na figura 1.

Figura 1 - Trajeto previsto e postos de fronteira do Corredor Bioceânico Internacional.

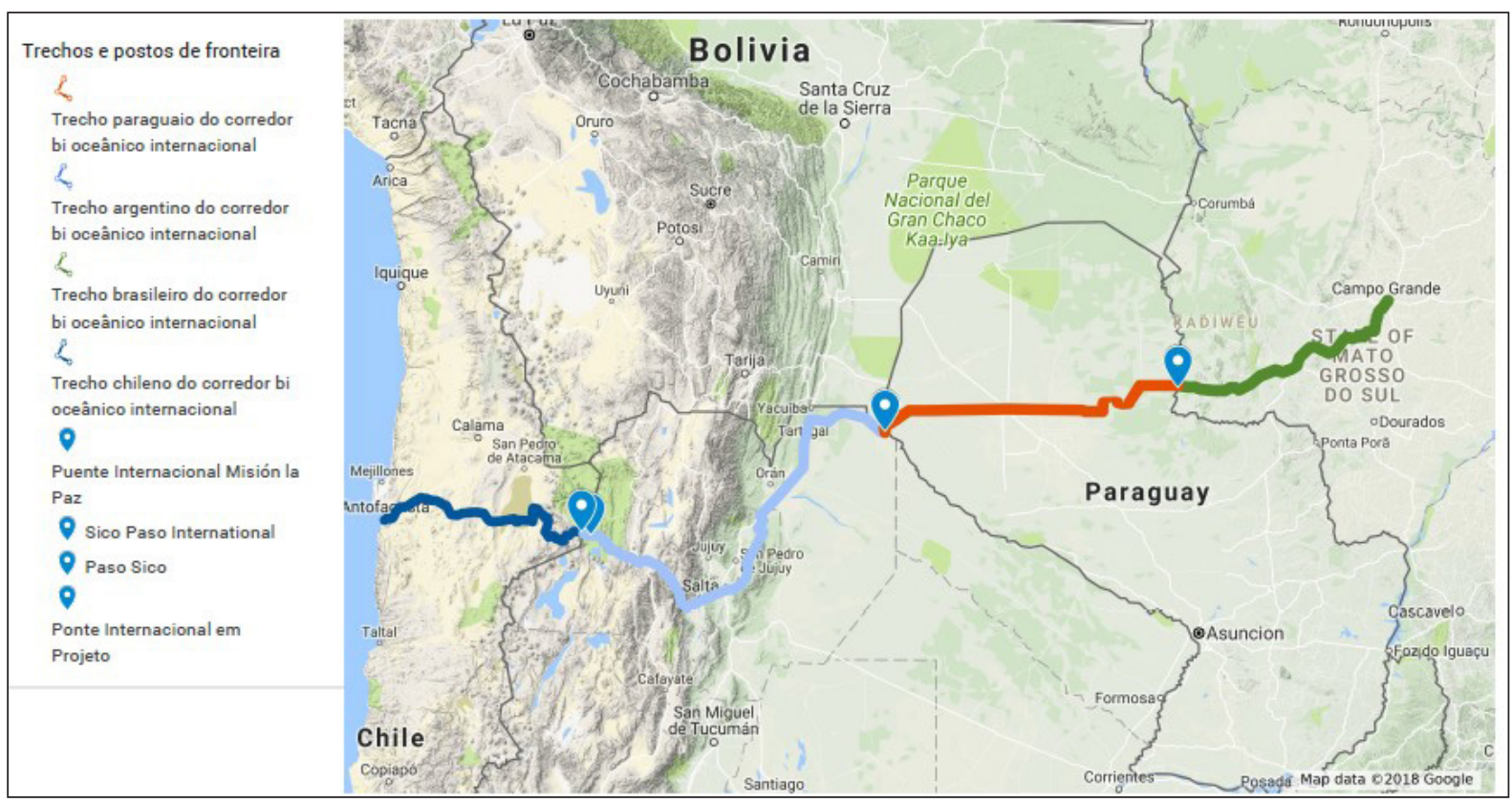

Fonte: Elaborado com o Google Maps com base em informações publicadas pelas fontes oficiais na imprensa (PORTAL G1, 2018).

Ao longo da toda o Corredor previst0 ainda não existe uma boa infraestrutura para atender aos viajantes e aos turistas de maneira satisfatória. Postos de fronteira com deficiência de pessoal, rodovias em más condições ou ainda inexistentes, problemas de segurança e deficiências para socorro mecânico, entre outros problemas de segurança marcam o percurso previsto em todos os países envolvidos, sem deixar de mencionar que no trecho do Paraguai a rodovia que comporá o Corredor Rodoviário, um trecho de aproximadamente $650 \mathrm{~km}$, ainda não está pavimentada (PORTAL G1, 2018). 
Um dos desafios ao longo do Corredor será o de melhorar a infraestrutura e estabelecer políticas que aumentem o conforto e a segurança de viajantes com especial atenção para as potencialidades turísticas existentes. Ao longo de todo o trecho previsto se observa um bom potencial turístico com recursos e atrativos, principalmente nos segmentos do ecoturismo, cultura e gastronomia.

As restrições provocadas pelo imperativo de se manter barreiras de segurança nas fronteiras devem se manter ainda por muito tempo, mas, para melhorar o conforto e a experiência dos viajantes, a adoção de novas tecnologias poderá atenuar esses desconfortos. A adoção de passaportes eletrônicos e de sistemas de reconhecimento facial, ainda que provoquem controvérsias em razão das questões de privacidade, pode resolver o problema de demora nos postos de fronteira. Estas questões são discutidas por pesquisadores como Del Rio et al. (2016) e são levadas a sério, por exemplo, por autoridades do Reino Unido (UK PASSPORT..., 2013).

A partir das percepções de operadores e agências de turismo que atuam nos países envolvidos no Corredor Bioceânico foi organizado o quadro a seguir (Quadro 1) com as barreiras específicas encontradas nas fronteiras.

Quadro 1 - Documentações exigidas para circulação de turistas dos/para os países do projeto do Corredor Bioceânico Internacional

\begin{tabular}{|c|c|c|c|c|}
\hline & Paraguai & Argentina & Chile & Brasil \\
\hline $\begin{array}{l}\text { Documentos } \\
\text { Exigidos }\end{array}$ & \multicolumn{4}{|c|}{$\begin{array}{c}\text { Documento de Identidade Civil* em bom estado de conservação, e que permita a } \\
\text { identificação do portador, ou Passaporte válido }\end{array}$} \\
\hline $\begin{array}{l}\text { Ação para } \\
\text { entrar no país }\end{array}$ & \multicolumn{4}{|c|}{$\begin{array}{l}\text { Emissão de Permissão / Permiso expedido pela Aduana, mediante apresentação dos } \\
\text { documentos exigidos, realizada com a presença do próprio solicitante. }\end{array}$} \\
\hline $\begin{array}{l}\text { Transição de } \\
\text { Veículos }\end{array}$ & $\begin{array}{l}\text { Carro de Passeio: } \\
\text { Habilitação válida } \\
\text { do país de origem, } \\
\text { Seguro Carta Verde. } \\
\text { Veículos transporte } \\
\text { de Passageiros } \\
\text { (Ônibus, Vans e } \\
\text { Microônibus): } \\
\text { Além das exigências } \\
\text { acima é preciso ter } \\
\text { DINATRAN }\end{array}$ & $\begin{array}{l}\text { Carro de Passeio: } \\
\text { Habilitação válida } \\
\text { no país de origem, } \\
\text { Seguro Carta Verde, } \\
\text { Extintor de incêndio } \\
\text { e dois triângulos de } \\
\text { sinalização } \\
\text { Veículos } \\
\text { transporte de } \\
\text { Passageiros } \\
\text { (Ônibus, Vans e } \\
\text { Microônibus): } \\
\text { Além das } \\
\text { exigências acima é } \\
\text { preciso ter SST }\end{array}$ & $\begin{array}{l}\text { Carro de Passeio: } \\
\text { Habilitação válida } \\
\text { no pais de origem, } \\
\text { Seguro Carta } \\
\text { Verde, Extintor } \\
\text { de incêndio, dois } \\
\text { triângulos de } \\
\text { sinalização e colete } \\
\text { refletivo. } \\
\text { Veículos } \\
\text { transporte de } \\
\text { Passageiros } \\
\text { (Ônibus, Vans e } \\
\text { Microonibus): } \\
\text { Além das } \\
\text { exigências acima é } \\
\text { preciso ter registro } \\
\text { regulamentado no } \\
\text { órgão local }\end{array}$ & $\begin{array}{l}\text { Carro de Passeio: } \\
\text { Habilitação válida } \\
\text { no país de origem, } \\
\text { Seguro Carta } \\
\text { Verde, conjunto } \\
\text { de estepe, extintor } \\
\text { de incêndio e } \\
\text { triangulo de } \\
\text { sinalização. } \\
\text { Veículos } \\
\text { transporte de } \\
\text { Passageiros } \\
\text { (Ônibus, Vans e } \\
\text { Microonibus): } \\
\text { Além das } \\
\text { exigências } \\
\text { acima é preciso } \\
\text { solicitar licença } \\
\text { complementar da } \\
\text { ANTT }\end{array}$ \\
\hline
\end{tabular}




\begin{tabular}{|c|c|c|c|c|}
\hline & Paraguai & Argentina & Chile & Brasil \\
\hline Vacinas & \multicolumn{3}{|c|}{$\begin{array}{l}\text { Vacina de Febre Amarela obrigatório para brasileiros de estados } \\
\text { de risco (devendo ter sido tomada com no mínimo } 10 \text { dias } \\
\text { de antecedência da viagem e estar registrada em Carteira } \\
\text { Internacional de Vacinação emitida pela Anvisa) }\end{array}$} & $\begin{array}{c}\text { Não há } \\
\text { obrigatoriedade, } \\
\text { mas recomenda-se } \\
\text { que os viajantes } \\
\text { atualizem sua } \\
\text { situação vacinal } \\
\text { antes da viagem, } \\
\text { especialmente se } \\
\text { forem para regiões } \\
\text { de risco. }\end{array}$ \\
\hline Seguro Saúde & \multicolumn{4}{|c|}{ Não obrigatório, mas recomendado. } \\
\hline Moeda Aceita & $\begin{array}{c}\text { Guarani, Dólar ou } \\
\text { Cartão de Crédito } \\
\text { internacional }\end{array}$ & $\begin{array}{l}\text { Peso Argentino, } \\
\text { Dólar ou Cartão } \\
\text { de Crédito } \\
\text { internacional }\end{array}$ & $\begin{array}{l}\text { Peso Chileno, } \\
\text { Dólar ou Cartão } \\
\text { de Crédito } \\
\text { internacional }\end{array}$ & $\begin{array}{l}\text { Real ou Cartão } \\
\text { de Crédito } \\
\text { Internacional }\end{array}$ \\
\hline $\begin{array}{c}\text { Quantidade } \\
\text { de dinheiro } \\
\text { em espécie } \\
\text { que se } \\
\text { permite } \\
\text { portar }\end{array}$ & \multicolumn{3}{|c|}{$\begin{array}{c}\text { Não há limite de entrada de dinheiro, porém, valor igual ou } \\
\text { maior que U\$ 10.000,00 (dez mil dólares dos Estados Unidos) } \\
\text { por pessoa, ou equivalente em outras moedas, em espécie ou } \\
\text { instrumentos negociáveis, devem ser declarados no momento de } \\
\text { entrada no país. }\end{array}$} & $\begin{array}{c}\text { Valores em espécie } \\
\text { cujo total seja } \\
\text { igual ou superior } \\
\text { a R\$ 10.000,00 } \\
\text { (dez mil reais), } \\
\text { ou equivalente } \\
\text { em outras } \\
\text { moedas, devem } \\
\text { ser declarados à } \\
\text { Receita Federal } \\
\text { no ato de entrada } \\
\text { no país. Não } \\
\text { há cobrança de } \\
\text { tributos. }\end{array}$ \\
\hline
\end{tabular}

Fonte: elaborado pelos autores a partir de informações coletadas junto a operadores e agências de turismo nos países alvo da pesquisa, página eletrônica oficial do MERCOSUL, Ministério das Relações Exteriores do Brasil e Agência Nacional de Transportes Terrestre.

O quadro acima apresenta as exigências para que os cidadãos da Brasil, Paraguai, Argentina e Chile circulem nos países pertencentes ao futuro Corredor Rodoviário Bioceânico. Várias dessas exigências são estabelecidas por acordos firmados no âmbito do Mercado Comum do Sul (Mercosul). Embora o Chile não seja um país-membro do acordo, ele se enquadra como um estado membro associado ao Mercosul. Portanto adota algumas de suas resoluções.

Segundo acordo do Mercosul, assinado em 26 de março de 1991, os cidadãos dos países-membros ficam livres de apresentar passaporte, podendo viajar apenas com Cédula de Identidade Nacional (no caso de brasileiros, o Registro Geral [RG]). O acordo prevê que o documento deve estar em bom estado de conservação e permitir a identificação do portador. Nesse contexto, algumas aduanas estabelecem que o prazo de emissão deste documento dever ser de no máximo de 10 anos, a fim de garantir o estado de conservação e principalmente a possibilidade de identificação do portador. Entretanto, esse prazo específico não está descrito no documento assinado. O Chile, como membro associado do Mercosul, aderiu a esse acordo posteriormente e adota a mesma política para o ingresso de brasileiros em seu território.

Vale lembrar também, que mesmo antes do Mercosul, houve outras tentativas de acordo comercial e de livre circulação na América do Sul. Este é, por exemplo, o caso da Associação 
Latino-Americana de Livre Comércio (ALALC), de 1960, da qual o Chile fazia parte, e foram a base para as exigências atuais de circulação entre esses países. Faria (2004) retrata de forma breve a evolução desses tratados:

Embora as iniciativas de integração latino-americana sejam quase tão antigas quanto a da União Europeia (a ALALC é de 1960, enquanto a Comunidade Econômica Europeia foi fundada em 1957), sua efetividade, no sentido de uma evolução do processo que tenha significado econômico e social, só veio a se materializar nos anos 90. [...] O movimento integracionista que formou o MERCOSUL resultou da iniciativa de aproximação argentina e brasileira de meados dos anos 80 e se concretizou em 1991, quando, com a adesão do Paraguai e do Uruguai, foi firmado o Tratado de Assunção. (FARIA, 2004, p. 126).

O Paraguai é flexível quanto à data de emissão da Cédula de Identidade, que pode ter mais de 10 anos de expedição, sem data máxima ou mínima exigida, desde que esteja em bom estado de conservação, não manchada, rasgada ou rasurada. Caso o viajante interessado em ingressar nos países não possua cartão de identificação em conformidade com as exigências pactuadas entre os países, deverá apresentar Passaporte que esteja dentro do prazo de validade. O Chile e a Argentina são países que normalmente exigem que o documento de identificação dos brasileiros tenha menos de dez anos de expedição. Os operadores de turismo entrevistados relatam que, para evitar contratempos e dificuldades aos viajantes, sempre recomendam o uso de documento de identificação com até dez anos de emissão.

Outra documentação cuja exigência é comum entre os países, e estabelecida pela Resolução n. 120/1994, do Mercosul, é aquela necessária para a circulação e condução de veículos automotores. O acordo, do qual o Chile é signatário, permite que os cidadãos dos países, membros e associados signatários, possam conduzir veículos portando a Carteira de Habilitação válida em seu país. Para o veículo, além do documento do país de origem, é necessário portar Seguro Carta Verde, que cobre a responsabilidade civil do proprietário/condutor do veículo em caso de danos materiais ou pessoais causados em pessoas ou objetos não transportados. Além disso, o veículo deve possuir os equipamentos e acessórios de segurança exigidos pela legislação de trânsito do país visitado.

Para veículos de transporte coletivo de passageiros, tais como ônibus, vans e micro-ônibus, além das exigências acima, solicitadas para todos os veículos, deve-se obter autorização do órgão fiscalizador competente do país visitado. No caso do Brasil, a solicitação é feita à Agencia Nacional de Transportes Terrestre (ANTT).

Já na questão sanitária, como mostra o quadro 1, a vacinação contra a Febre Amarela é uma exigência em comum entre Paraguai, Argentina e Chile, sobretudo para brasileiros oriundos das regiões que apresentam risco da doença. A vacinação deve estar registrada em Carteira Internacional de Vacinação, que é expedida pela Agência Nacional de Vigilância Sanitária (Anvisa). Essa medida foi tomada devido aos surtos de febre amarela estarem cada vez mais frequentes no Brasil, o que fez com que vários países se preocupassem com a epidemia e solicitassem esse documento, que só é expedido após a vacina ser tomada com no mínimo 10 dias de antecedência (tempo para a vacina fazer efeito) e comprovada com carimbo e assinatura do posto onde foi tomada. Para cidadãos desses países, no momento o Brasil não exige vacinas específicas, mas recomenda que a situação vacinal do turista esteja atualizada. Essas recomendações podem ser alteradas conforme a identificação de necessidade pelas autoridades sanitárias de cada país.

Todos os documentos ser apresentados às autoridades de migração devem ser originais. 
Estes devem ser apresentados pelo próprio viajante no momento em que desejam adentrar um dos países. Porém ainda há dúvidas entre os operadores e as agências de turismo mais experientes em viagens pela América do Sul. Uma delas é se toda a documentação é realmente conferida pela aduana, ou, no caso de os agentes da aduana não solicitarem algum documento exigidos pelos agentes de imigração, se eles podem ser solicitados por outro órgão fiscalizador do país visitado.

A grande questão é que, por meio de questionário aplicado por esta pesquisa e também experiências vividas em viagens realizadas, muitas pessoas relatam que as aduanas são extremamente burocráticas quando o assunto é o documento de identidade nacional ou o passaporte. Porém outras situações, como a conferência de Carteira de Vacinação, ora são cobrados ora não, o que permitem brechas para uma solicitação posterior, deixando muitas vezes o visitante constrangido ou sujeito a exigências de autoridades aduaneiras ou policiais que, por vezes, criam dificuldades para exigir facilidades.

Essa afirmação decorre de várias respostas dos entrevistados, que relatam abusos por parte de autoridades locais, como a solicitação de propinas mediante ameaças, muitas vezes relacionados à própria documentação exigida, principalmente no Paraguai. Há relatos ainda de viajantes que entraram ilegalmente e foram detidos por autoridades policiais por terem sido flagrados comprando tais facilidades. Nesse contexto, há uma preocupação quanto à segurança, à fiscalização e à exploração com impactos negativos sobre a imagem do sistema turístico que aceita e permite certos tipos de corrupção.

Analisando ainda o Quadro 1, um documento que não é obrigatório, mas altamente recomendado, é o seguro de viagem. O site da agência E-trip (2017), especializada em viagens internacionais, define o seguro de viagem como "uma espécie de plano de saúde temporário, funcionando como uma garantia de indenização para diversas situações, incluindo acidentes e doenças. Ele é válido somente pelos dias da contratação e está limitado às normas especificadas em contrato". Ou seja, esses vouchers valem por período temporário e asseguram assistência para diversos contratempos que possam vir a acontecer durante a viagem, dependo dos serviços contratados.

Observa-se que tanto no Paraguai quanto na Argentina e no Chile o sistema de saúde público não é bom, já que a população local recorre normalmente a planos de saúde que dão acesso à rede particular de atendimento. A população local é amparada por um fundo previdenciário de cada país. Isso deixa os turistas sem alternativa em casos de infortúnios relacionados à saúde e até acidentes ou óbito, tendo que recorrer a instituições privadas e de alto valor comparados a uma apólice de seguro ou assistência viagem. No Brasil, os turistas podem ser atendidos, de forma emergencial, pelo Sistema Único de Saúde (SUS). O atendimento pode ser precário a depender da localidade e do posto de assistência.

Caso o viajante não tenha seguro e não consiga arcar com as despesas médicas pode ter que arcar com os altos custos de transporte desde o país visitado até o seu país de origem. Por outro lado, foram relatadas assistências ambulatoriais de menor monta e sem custo para os viajantes no interior da Argentina. Verifica-se em outros casos que alguns hotéis já possuem seguro assistência saúde aos seus hóspedes.

O receio com a vigilância sanitária e o consumo de alimentos foram aspectos citados pelos entrevistados, que demonstraram certa precaução com o consumo de alimentos, principalmente em cidades do interior dos países. Apesar da grande preocupação da Anvisa e das agências dos demais países, comprovados por meio de vários acordos firmados através de cooperação interna- 
cional, que podem ser encontrados no site da própria Anvisa, reportagem da Fundação Oswaldo Cruz infere que problemas sanitários são comuns em países da América do Sul (ESCANHO; SILVA, 2011). A matéria infere ainda que outro aspecto crucial, de acordo com os representantes das nações, está relacionado à falta de profissionais para colocar em prática a regulação pretendida.

Diante da situação de não-obrigatoriedade do Seguro, da precariedade do sistema público de saúde e dos problemas de vigilância sanitária que acometem a maior parte da América do Sul, os viajantes ficam à mercê da sorte, caso haja algum contratempo.

Outro fator a ser considerado na circulação de turistas pela América do Sul, em especial nos países integrantes do projeto do Corredor Bioceânico, é a questão do câmbio. Alguns dos entrevistados relatam dificuldades em manusear a moeda local e que, nos poucos lugares dos países estrangeiros que aceitam pagamento em Real, devolvem o troco com moeda local, dificultando a conferência. No entanto, disseram encontrar casas de câmbio com facilidade nas principais cidades que visitaram e que, além da moeda local, era aceito o dólar, ao contrário do que ocorre no Brasil, onde o viajante estrangeiro tem dificuldades para encontrar casas de câmbio especializadas e são poucos os estabelecimentos que recebem em dólar.

Quanto ao uso de cartão para pagamento, os entrevistados relataram que a maioria dos estabelecimentos do Paraguai, da Argentina e do Chile aceita apenas na função crédito. Poucos estabelecimentos não aceitavam cartão de crédito de forma alguma, devendo o turista portar dinheiro em espécie.

A grande questão apontada pelos turistas é a falta de uma moeda única. Então, se a intenção é visitar mais de um país, ao longo do Corredor Rodoviário Bioceânico, por exemplo, o planejamento da quantidade de moeda estrangeira a levar se torna uma dificuldade adicional, pois é preciso avaliar bem se a melhor opção é levar dólar, usar o cartão de crédito internacional ou levar real e trocar diretamente por moedas locais.

Nos quatro países não há um limite de valor em espécie que se possa portar na entrada do país. Entretanto, no Paraguai, no Chile e na Argentina, valores acima de dez mil dólares americanos, ou equivalente em outras moedas, devem ser declarados logo na entrada do país. No Brasil, segundo o site do Ministério das Relações Exteriores, valor igual ou acima de dez mil reais deve ser declarado na entrada do país.

\section{CONSIDERAÇÕES FINAIS}

Embora sejam apontadas várias vantagens econômicas acerca da criação do Corredor Bioceânico, também conhecido como Rota de Integração Latino-Americana (Rila), a presente pesquisa expôs e relatou vários aspectos a serem considerados antes da consolidação do mesmo.

Apesar de a prática do turismo não ser o principal objetivo do Corredor, vale lembrar que os países envolvidos têm grande parte da economia atrelada ao consumo turístico espalhada em várias regiões e que têm um potencial muito grande para desenvolver ainda mais, principalmente nas cidades ao longo do Corredor, mas para isso não pode ser desconsiderada a atual situação a que a atividade está exposta e é necessário buscar melhorias para se extrair um bom resultado ao projeto.

Conforme descrito por pessoas que viajaram recentemente aos países integrantes do Corredor Bioceânico e responderam ao questionário desta pesquisa, ainda existe uma deficiência muito grande em relação aos serviços turísticos, principalmente no tocante à saúde, à 
segurança, à vigilância sanitária e aos meios de pagamento, quesitos esses que vão muito além do trade turístico, mas que interferem diretamente na prática do turismo e principalmente na livre circulação de pessoas.

Para o setor de hospitalidade é imperativo o planejamento prévio da redução dos impactos negativos do turismo e sobre os turistas e a interação deste setor com as instâncias de governança locais que decidem sobre segurança, saúde e sistemas de pagamento.

Pôde-se perceber, ao longo da discussão, que existem soluções para aumentar o conforto dos viajantes e reduzir os efeitos do descontrole que permitem práticas de corrupção. Entretanto, ações que melhorem o atendimento nos postos de fronteira, com o aumento das opções de pagamento e o atendimento às questões de saúde e segurança dependem de uma maior integração entre as instâncias governamentais dos quatro países envolvidos.

Tal integração só existirá se o sistema de hospitalidade e turismo e as instâncias de governança conseguirem convencer as demais instâncias sobre a importância de se preservar a integridade e o conforto dos turistas, por sua importância para o desenvolvimento local.

O grande desafio é consolidar o intuito comercial do Corredor com a prática da atividade turística, não negligenciando a atual realidade e aliviando os desconfortos relatados pelos viajantes, através de medidas que potencializam a hospitalidade e assim seja possível um maior impacto positivo com a construção do Corredor Rodoviário Bioceânico.

\section{REFERÊNCIAS}

ESCANHO, T.; SILVA, E. Problemas na vigilância sanitária são comuns em países da América do Sul. Agencia Fiocruz de Noticias, Rio de Janeiro, nov. 2011. Disponível em: https://agencia.fiocruz.br/problemas-navigil\%C3\%A2ncia-sanit\%C3\%A1ria-s\%C3\%A3o-comuns-em-pa\%C3\%ADses-da-am\%C3\%A9rica-do-sul. Acesso em: out. 2018.

UK PASSPORT authorities tender for facial recognition. Biometric Technology Today, n. 4, News, abr. 2013. Disponível em https://www.journals.elsevier.com/biometric-technology-today. Acesso em: out. 2018.

BANCO NACIONAL DE DESENVOLVIMENTO ECONÔMICO E SOCIAL (BNDES). Estudos Técnicos Referentes ao Eixo de Capricórnio: avaliação dos Corredores Bioceânicos. Brasília: BNDES, 2010. Disponível em: https://www.bndes.gov.br/arquivos/corredor-bioceanico/. Acesso em: set. 2018.

BRADBURY, S. L. Irritable Border Syndrome: the Impact of Security on Travel Across the Canadá - U.S. Border. Canadian-American public policy, n. 79, dec. 2012. Disponível em: https://journals.uvic.ca/index. php/capp/article/view/16540. Acesso em: set. 2018.

BUHALIS, D.; LAW, R. Progress in information technology and tourism management: 20 years on and 10 years after the Internet-The state of eTourism research. Tourism Management, n. 29, p. 609-23, 2008. Disponível em: <>. Acesso em: ago. 2018.

BUTLER, R. W. The concept of a tourist area cycle of evolution: implications for management of resources. Canadian Geographer, v. 4, n. 1, p. 5-12, 1980. Disponível em: https://onlinelibrary.wiley.com/doi/ abs/10.1111/j.1541-0064.1980.tb00970.x. Acesso em: ago. 2018.

DEL RIO, J. S.; MOCTEZUMA, D.; CONDE, C.; DE DIEGO, I. M.; CABELLO, E. Automated border control e-gates and facial recognition systems. Computer \& Security, n. 62, p. 49-72, 2016. Disponível em: https://www. sciencedirect.com/science/article/pii/ S0167404816300736. Acesso em: out 2018. 
E-TRIP. Saiba por que é tão importante contratar um seguro de viagem, set. 2017. Disponível em: https:// etrip.com.br/saiba-por-que-e-tao-importante-contratar-um-seguro-de-viagem/. Acesso em: out. 2018.

FARIA, L. A. E. A chave do tamanho: desenvolvimento econômico e perspectivas do mercosul. Porto Alegre: Editora da UFRGS/Fundação de Economia e Estatística Siegfried Emanuel Heuser, 2004.

FERNANDES, R. M. S. A Rota Rodoviária Bioceânica como instrumento de interação entre discursos e práticas em umaZona de Fronteira: uma rodoviae vários caminhos. Orientador:Adáuto deOliveiraSouza. 2012.218f. Dissertação (Mestrado em Geografia)- Universidade Federal da Grande Dourados, Dourados, MS, 2012. Disponível em: http://files.ufgd.edu.br/arquivos/arquivos/78/MESTRADO-DOUTORADO-GEOGRAFIA/Disserta\%C3\%A7\% C3\%A3o(30).pdf. Acesso em: ago. 2018.

GOELDNER, C. R.; RITCHIE, J. R. B.; MCINTOSH, R.W. Turismo: princípios, práticas e filosofias. 8. ed. São Paulo: Bookman, 2002.

HINTZE, H.; ALMEIDA JUNIOR, A. R. Freedom to travel or freedom to trade? A critical analysis of the WTTC discourse. Turismo \& desenvolvimento, n. 21/22, 2014. Disponível em: http://revistas.ua.pt/index.php/ rtd/article/viewFile/8589/6948. Acesso em: ago. 2018.

JAEGER JÚNIOR, A. Mercosul e a Livre Circulação de Pessoas. Orientadora: Odete Maria de Oliveira. 1999. 169fl. Dissertação (Mestrado em Direito) - Universidade Federal de Santa Catarina, Florianópolis, SC, 1999. Disponível em: http://repositorio.ufsc.br/xmlui/handle/123456789/81379. Acesso em: ago. 2018.

KWANISAI, G.; MPOFU, T.; VEGESAYI, S.; MUTANGA, C. HUROMBO, B.; MIRIMI, K. Borders as barriers to tourism: tourists experiences at the Beitbridge Border Post (Zimbabwean side). African Journal of Hospitality - Tourism and Leisure, v. 3, n. 1. 2014. Disponível em: http://www.ajhtl.com/uploads/7/1/6/3/7163688/ article_48_vol_3_1.pdf. Acesso em: ago. 2018.

MERCOSUR. [S.d.]. Disponível em: https://www.mercosur.int/. Acesso em: dez. 2018.

MIDDLETON, V. T. C. Marketing de turismo: teoria e prática. Rio de Janeiro: Campus, 2002.

MIGIRO, S. O.; OCHOLA, D. N. Information and Communication Technologies in Small and Medium Scale Tourism Enterprises in Durban, South Africa. SAGE Publications, v. 21, n. 4, 2005. Disponível em: http:// journals.sagepub.com/doi/ 10.1177/0266666905060089. Acesso em: ago. 2018.

MORRINSON, A. M. Marketing de Hospitalidade e Turismo. São Paulo: Cengage Learning, 2012.

PETROCCHI, M. Gestão de polos turísticos. São Paulo: Futura, 2001.

PLOG, S. Why destination areas rise and fall in popularity. Cornell Hotel and Restaurant Quarterly, v. 14, n. 4, p. 55-8, 2001. Disponível em: http://journals.sagepub.com/doi/abs/ 10.1177/0010880401423001.

PORTAL G1. Notícias do corredor oceânico da Rota de Integração Latino Americana. Disponível em: http:// g1.globo.com/mato-grosso-do-sul/rila/. Acesso em: out. 2018.

RICHTER, L. K.; WAUGH, W. Terrorism and tourism as logical companions. Tourism Management, v. 7, n. 4, p. 230-38, 1986. Disponível em: https://www.researchgate.net/ publication/276954760_Terrorism_ and_tourism_as_logical_companions. Acesso em: set. 2018.

RICHTER, L. K.; RICHTER, W. L. Ethics Challenges: Health, Safety and Accessibility in International Travel and Tourism. Public Personnel Management, v. 61, n. 28, 1999. Disponível em: http://journals.sagepub. com/doi/abs/10.1177/009102609902800408. Acesso em: 13 set. 2018. 
URRY, J. O olhar do turista: lazer e viagens na sociedades contemporâneas. São Paulo: Nobel, 1996.

WORLD TOURISM BAROMETER (UNWTO), v. 16, n. 3, jun. 2018. Disponível em: http://www.unwto.org. Acesso em: jul. 2018.

WORLD TRAVEL \& TOURISM COUNCIL (WTTC). Evaluation of job creation in G20 countries through maximising infrastructure: Capacity through technology that facilitates travel and integrates security. Argentina, 2018. Disponível em: https://www.wttc.org/-/media/files/reports/2018/ wttc--g20-jobscreation-white-paper-en.pdf. Acesso em: jul. 2018.

$\mathrm{XU}, \mathrm{H}$.; BAO J.; ZHOU C. Effectiveness of regional tourism integration: case of quadrangle economic cooperation zone in Great Mekong region. Chinese Geographical Science, Beijing, China, v., 16, n. 2, p. 141-7, 2006. Disponível em: http://egeoscien.neigae.ac.cn/CN/abstract/abstract8677.shtml. Acesso em: jul. 2018.

\section{Sobre os autores:}

José Roberto da Silva Lunas: Doutor em Desenvolvimento Sustentável pela Universidade de Brasília. Administrador pela Universidade da Grande Dourados. Professor Adjunto da Universidade Estadual de Mato Grosso do Sul. E-mail: Iunas_uems@yahoo.com.br, Orcid: http://orcid.org/0000-0002-3340-8315

Aline Santos Melo: Bacharel em Turismo. E-mail: ninimelo@hotmail.com, Orcid: http://orcid.org/0000-0001-8371-3484

Maria Cristiane Fernandes da Silva Lunas: Doutorado e Mestrado em Meio Ambiente e Desenvolvimento Regional pela Universidade Anhanguera-UNIDERP. Graduada em Turismo com Ênfase em Ambientes Naturais (2006) e especialista em Planejamento e Gestão Ambiental com ênfase em Avaliação Ambiental Estratégica, ambos pela Universidade Estadual de Mato Grosso do Sul (UEMS). Professora na UEMS. E-mail: crisfernandes_tur@hotmail.com, Orcid: http://orcid.org/0000-0001-5493-6005 
